\title{
Raman spectra and electron microscopic investigations of the sections of modified $\mathrm{As}_{2} \mathrm{~S}_{3}$ glasses
}

\author{
N. Mateleshko, V. Mitsa, E. Borkach \\ Uzhgorod National University, 32, Voloshin str., 88000 Uzhgorod, Ukraine \\ E-mail: mitsa@univ.uzhgorod.ua
}

\begin{abstract}
Chalcogenide vitreous semiconductors (ChVS) are used as memory elements, elements of fiber, integral and power optics [1-6]. The change of the synthesis conditions results in the change of structure and, as a consequence, physical parameters of ChVS [1]. It means that it is possible to find solution of the fabrication of glasses with high optical strength by using modification of ChVS structure [2]. The objective of the present work is to investigate the influence of the temperature-temporal conditions of the fabrication on the structure of $\mathrm{As}_{2} \mathrm{~S}_{3}$ glasses by the method of the Raman scattering spectroscopy and electron microscopy and also to choose the conditions of fabrication of $\mathrm{As}_{2} \mathrm{~S}_{3}$ glasses with the continuously bonded matrix of the structure suitable for power optics using this basis.
\end{abstract}

Keywords: chalcogenide glasses, arsenicum trisulfide, Raman scattering spectroscopy.

Paper received 03.03.04; accepted for publication 21.10.04.

\section{Introduction}

The investigation of the non-crystalline semiconductors is one of the important objectives of the solid state physics. The problem to modify properties of these materials up to date still remains actual. The technological modification is among the effective methods directed towards the solution of this problem. The change of the synthesis temperature and cooling rate results in the changing structure, which causes changes in materials properties.

\section{Experimental technique}

During fabrication of $g-\mathrm{As}_{2} \mathrm{~S}_{3}$, the temperature-temporal conditions of the annealing were modified. The aim was to choose fabrication conditions, which enable to avoid dissociation of the structural units (s.u.) in the melt. As the technological modification of the $g-\mathrm{As}_{2} \mathrm{~S}_{3}$ fabrication we will imply the change of the melt temperature $\left(T_{i}\right.$, $i=1,2,3)$, from which the cooling started $\left(T_{1}=870 \mathrm{~K}\right.$; $\left.T_{2}=1170 \mathrm{~K} ; T_{3}=1370 \mathrm{~K}\right)$ and change of the melt cooling rate $\left(V_{1}=10^{-2}, \mathrm{~V}_{2}=1,5 ; V_{3}=1.5 \times 10^{2} \mathrm{~K} / \mathrm{s}\right)$. Investigations of the Raman spectra was carried out using DFS-24 spectrophotometer. He-Ne laser $(\lambda=632.8 \mathrm{~nm})$ was used to excite Raman scattering.

Electron-microscopic investigations of modified $g$ - $\mathrm{As}_{2} \mathrm{~S}_{3}$ were carried out using sections $g-\mathrm{As}_{2} \mathrm{~S}_{3}$, which were obtained using UMTP-4 ultramicrotome, the thickness of the samples 50-70 nm was small enough for transmitting the electron beams [7].

\section{Results and discussion}

Within the frames of the molecular approach (model) [8] most intensive band in the Raman spectra of $g-\mathrm{As}_{2} \mathrm{~S}_{3}$ near $340 \mathrm{~cm}^{-1}$ (Fig. 1, 2) in the first approximation can be interpreted stemming from the frequencies of free molecule analogs and related to the symmetric vibrations of $\mathrm{AsS}_{3}$ pyramid with $C_{3} v$ symmetry [9].

In the Raman spectra of $g-\mathrm{As}_{2} \mathrm{~S}_{3}$ in the wide band the high- and lowfrequency shoulders are observed at 380 and $316 \mathrm{~cm}^{-1}$, respectively (Fig.1). The fixation of the shoulder near $380 \mathrm{~cm}^{-1}$ in the Raman spectra of $g-\mathrm{As}_{2} \mathrm{~S}_{3}$ testify on the presence of the interaction between pyramids and creation of the "waterlike" bonds As-S-As [9]. Thus, in Raman spectra of $g-\mathrm{As}_{2} \mathrm{~S}_{3}$ it is possible to separate at least three bands. If the most intensive maximum can be related to the valence vibrations of $\mathrm{AsS}_{3}$ pyramids, then interpretation of the bands in Raman spectra is difficult, that points to the limitations of the use of "molecular" approach for the structural interpretation of the vibrational spectra of $g-\mathrm{As}_{2} \mathrm{~S}_{3}$.

Despite the moderate melt cooling rates from $870 \mathrm{~K}$, in Raman spectra of $g-\mathrm{As}_{2} \mathrm{~S}_{3}\left(T_{1} V_{1}\right)$ (Fig. 1) the band near 


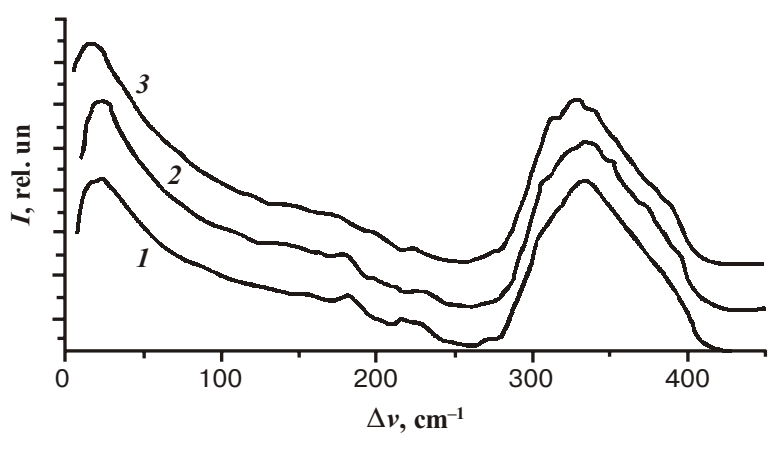

Fig. 1. Raman spectra of $\mathrm{As}_{2} \mathrm{~S}_{3}$ glasses obtained by melt $\left(T_{m 1}=\right.$ $=870 \mathrm{~K}$ ) cooling at different cooing rates $V_{j}: 1-V_{1}=10^{-2} \mathrm{~K} / \mathrm{s}$; $2-V_{2}=1.5 \mathrm{~K} / \mathrm{s} ; 3-V_{3}=1.5 \cdot 10^{2} \mathrm{~K} / \mathrm{s}$.

$230 \mathrm{~cm}^{-1}$ appears, which is characteristic for the atoms vibrations in $a$-As [9] and low-intensity band near $190 \mathrm{~cm}^{-1}$, characteristic for the vibrations of the atoms in $\mathrm{As}_{4} \mathrm{~S}_{4}$ "molecules" [10]. In the $450-480 \mathrm{~cm}^{-1}$ range, weak bands are pronounced, which are characteristic for S-S bonds [11]. The presence of the homopolar As-As bands testify on the partial dissociation of the pyramidal $\mathrm{AsS}_{3 / 2}$ s.u., which is reflected in their physical characteristics [2]. Chemical analysis of As-As bonds content in $g-\mathrm{As}_{2} \mathrm{~S}_{3}$ glasses shows that their general fraction consists $0.5 \mathrm{wt} \%$ [9], and $\mathrm{As}_{4} \mathrm{~S}_{4}$ content in this case is $\sim 0.015 \mathrm{~mol} . \%$, if rigid cooling conditions are used it is increased up to $0.15 \mathrm{~mol} . \%$ [12].

According to the cluster topological approach [13], generalized in [9], the intensive vibrational band in the low-frequency (LF) Raman spectrum of $g-\mathrm{As}_{2} \mathrm{~S}_{3}$ (synthesized from $870 \mathrm{~K}$ with the $1.5 \mathrm{~K} / \mathrm{s}$ cooling rate) with the maximum near $26 \mathrm{~cm}^{-1}$ coincides with the frequency of the rigid-layer vibrations in the Raman spectrum of $c-\mathrm{As}_{2} \mathrm{~S}_{3}$ crystal [2] and indicates presence in the glass matrix of the fragments, which are characteristic to the chain-layer ordered phase. The existence of the layerlike blocs in the structure of $g-\mathrm{As}_{2} \mathrm{~S}_{3}$ is supported by the presence of the first sharp diffraction peak (FSDP), observed in diffraction studies of the binary ChVS [4]. The

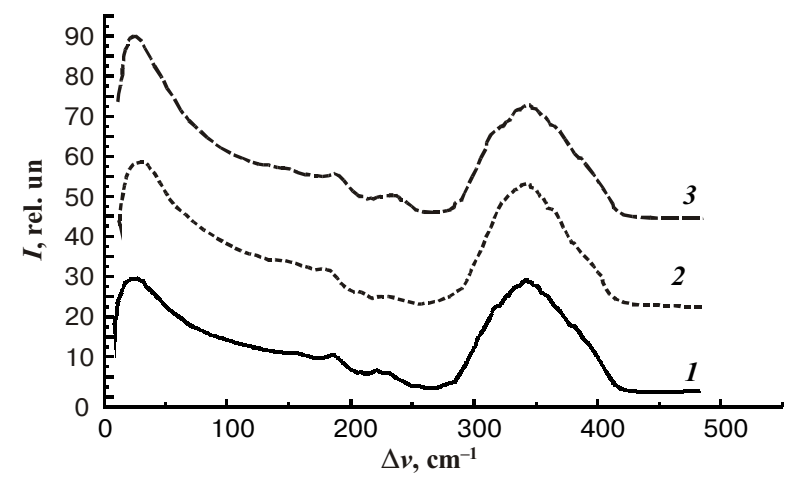

Fig. 2. Raman spectra of glasses, obtained with the constant cooling rate $\left(V_{1}=10^{-2} \mathrm{~K} / \mathrm{s}\right)$ from melts with different temperatures $T_{m i}: 1-T_{m 1}=870 \mathrm{~K} ; 2-T_{m 2}=1170 \mathrm{~K} ; 3-T_{m 3}=1370 \mathrm{~K}$. simplest model of $g-\mathrm{As}_{2} \mathrm{~S}_{3}$ structure is randomly oriented spiral chains of $\mathrm{AsS}_{3}$ pyramids [4]. In [14], it is shown that for formation of a layered fragment, it is sufficient that the chains will be parallel to each other.

Let us consider the position change of the low-frequency boson maximum $B$ in the Raman spectrum of the technologically modified $g-\mathrm{As}_{2} \mathrm{~S}_{3}$ (Figs 1, 2). The analysis of the position change of the low-frequency boson maximum $\mathrm{B}$ shows that the low-frequency maximum is shifted from $26 \mathrm{~cm}^{-1}\left(T_{1} V_{1}\right)$ up to $20 \mathrm{~cm}^{-1}\left(T_{3} V_{3}\right), T_{1}=$ $=870 \mathrm{~K} ; T_{2}=1170 \mathrm{~K} ; T_{3}=1370 \mathrm{~K}$ with the growth of the cooling rate $\left(V_{i}\right)$ from Ti temperatures. Anomalous shift is observed at low-temperature synthesis T1V1 in comparison with its position at $T_{1} V_{2}$. Here, B is shifted from $26 \mathrm{~cm}^{-1}\left(T_{1} V_{1}\right)$ up to $27 \mathrm{~cm}^{-1}\left(T_{1} V_{2}\right)$. The lowering of the frequency position of the boson maximum with the increase of cooling rate of the glasses was also observed in [9], but at temperatures close to the glass transition temperature of the arsenic trisulfide $\left(T_{g}=473 \mathrm{~K}\right)$. It is essential to note that with the change of the cooling rate we observed the increase of the ratio of the intensity of the boson maximum $\left(I_{B}\right)$ to the $\left(I_{342}\right)$ intensity of the valence vibrations of the As-S bonds in the Raman spectra near $342 \mathrm{~cm}^{-1}, \frac{I_{B}}{I_{340}}$, which is distinctly observable for the melt temperature $T_{3}$, where this ratio sharply increases from $0.96\left(T_{3} V_{1}\right)$ up to $1.27\left(T_{3} V_{2}\right)$, and further at $T_{3} V_{3}$ is practically unchanged. The increase of $\frac{I_{B}}{I_{340}}$ ratio points to the essential disordering of the structure of the matrix and agrees with the conclusions, which were obtained by means of the structural interpretation of the valence vibrations in the vibrational spectra of the modified $g-\mathrm{As}_{2} \mathrm{~S}_{3}$ [2]. According to the data of the electronmicroscopic studies in the matrix of such glass, the microcrystals with the sizes from 20.0 up to $50.0 \mathrm{~nm}$ are observed, so the shift of the boson maximum towards the low-frequency region at $T_{3} V_{3}$ conditions is logically to connect the destruction of the intactness of the matrix of the structure, which arises as a result of the emergence of the crystalline phase.

The results of the direct electron-microscopic investigations of the structure of $g-\mathrm{As}_{2} \mathrm{~S}_{3}\left(T_{1} V_{2}\right)$ show the high glass uniformity, absence of inclusions and uniform evaporation under the electron beam.

It is considered that the slow melt cooling with the soaking at $T_{1}=870 \mathrm{~K}$ (minimal temperature when the synthesis process undergoes within the real time scale) facilitates fabrication of the glass with the low defects number [4].

In the image of cleavage of $g-\mathrm{As}_{2} \mathrm{~S}_{3}$ (T1V1), inclusions are clearly observed (see Fig. 3), which are seen as dark dots on the uniform background. The theoretical calculations allow the possibility of the presence of 20 different s.u. in As-S system [9].

At the transition from moderate up to rigid conditions of the cooling, the content of As-As bonds in $g-\mathrm{As}_{2} \mathrm{~S}_{3}$ increases from 0.5 to $2.5 \mathrm{wt} . \%$ [9]. Thus. it is logically to 


\section{N. Mateleshko et al.: Raman spectra and electron microscopic investigations of ...}

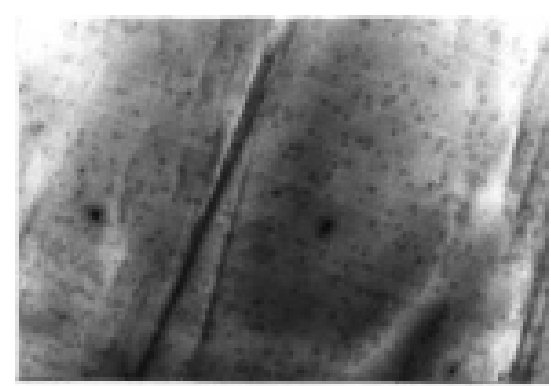

1

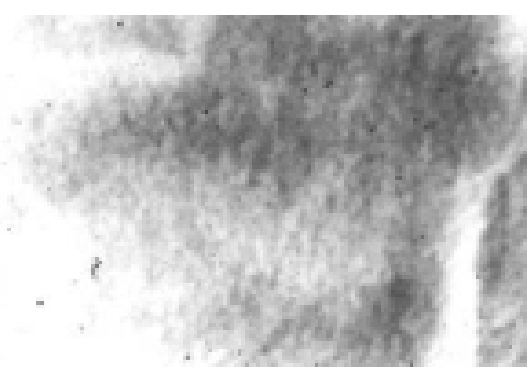

2

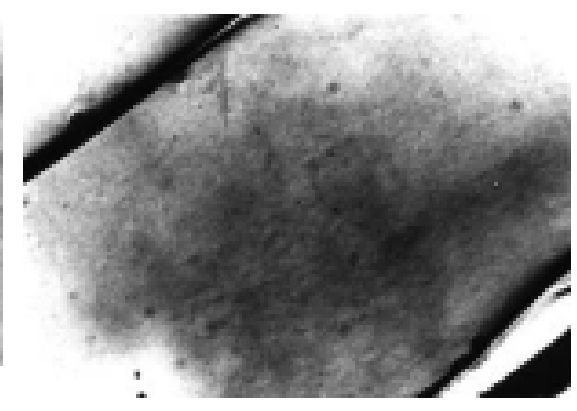

3

Fig. 3. Electron-microscopic images of the $g-\mathrm{As}_{2} \mathrm{~S}_{3}$, obtained in different physico-technological conditions [7]: $1-T_{1} V_{1} ; 2-T_{1} V_{2} ; 3-T_{1} V_{3}$.

suppose that the dark dots of $g-\mathrm{As}_{2} \mathrm{~S}_{3}\left(T_{1} V_{1}\right)$ observed in the microscope are related to the associates of arsenic, the existence of which is supported by the analysis of the vibrational spectra (Fig. 1, curve 1).

In the conditions of the rigid cooling of the melt $T_{1} V_{3}$ on the cleavage of the glass the voids are observed, filled by the pseudogranules of amorphous structure. These voids can be represented as bubbles of vapor, which are created in the glass volume during melt cooling. The dominating constituents of the vapor phase of $a-\mathrm{As}_{2} \mathrm{~S}_{3}$ in the wide temperature range are spherically symmetrical $\mathrm{As}_{4} \mathrm{~S}_{4}$ molecules [11]. Absorption edge of the molecular crystals $\alpha, \beta-\mathrm{As}_{4} \mathrm{~S}_{4}$ (the basic structural element of them are $\mathrm{As}_{4} \mathrm{~S}_{4}$ molecules) is shifted with reference to absorption edge of $g-\mathrm{As}_{2} \mathrm{~S}_{3}$ towards high-energy side [9]. Indeed, the absorption edge of $g-\mathrm{As}_{2} \mathrm{~S}_{3}$ which were obtained in different cooling conditions $\left(T_{1} V_{3}, T_{2} V_{3}, T_{3} V_{3}\right)$, is shifted to the high-energy side as compared with $T_{1} V_{2}$ conditions.

When cooling the melt from $T_{2}, T_{3}$, let us take into account that the melting temperature $T_{\text {melt }}\left(\mathrm{As}_{2} \mathrm{~S}_{3}\right)=$ $=583 \mathrm{~K}$ and boiling temperature $T_{\text {boil }}\left(\mathrm{As}_{2} \mathrm{~S}_{3}\right)=996 \mathrm{~K}$ are taken at the pressure 1 atmosphere [9]. With taking into account the value of $T_{\text {boil }}$, the cooling process from $T_{2}, T_{3}$ of the dissociation products of this overheated melt placed in the evacuated quartz ampoule must be similar to the process of the films fabrication [9]. If we suppose preferable influence of the structural factor on the optical damage threshold, then $I_{13}$ of $g-\mathrm{As}_{2} \mathrm{~S}_{3}\left(T_{1} V_{3}\right)$ coin- cides in its value with $I=30 \mathrm{MW} / \mathrm{cm}^{2}$ value of the $a$ $\mathrm{As}_{2} \mathrm{~S}_{3}$ film, which was obtained by the common crucible evaporation of the glass with the consequent vapor condensation on the unheated substrate [9]. The vapor phase of $a-\mathrm{As}_{2} \mathrm{~S}_{3}$ mainly consists of the complexes of $\mathrm{As}_{n} \mathrm{~S}_{m}$ ( $n, m=1 . .4$ type), and, what's more, the fraction of the $\mathrm{As}_{4} \mathrm{~S}_{4}$ fragments in the vapor is maximal [15]. It is known that the most stable component of the cluster flux "cools" on the substrate and in the condensed phase, as a rule, it is labile. The question arises on the character of the distribution of the dissociation products of the melt in the glass volume. Under $T_{2} V_{3}$ condition (Fig. 4) the glass has non-uniform wavy structure. At the cleavage, also observed are the chaotically placed electron-amorphous regions with widths up to $1000 \AA$. In the amorphous field of the diffraction pattern of the sample cooled from $T_{3} V_{3}$ the reflexes are observed, which testify on the presence of the crystalline inclusions of sulfur in the sample. The evaluation of their sizes has shown that it is varied from 200 up to $500 \AA$. The ascent of the "plateau" in the lowenergy part of the absorption $\alpha$ curve is similar to that observed in ChVS with the presence of microscopic inclusions [4].

The vitreous $g$ - $\mathrm{As}_{2} \mathrm{~S}_{3}$ practically does not crystallize [4], the appearance of the microcrystalline inclusions in the glasses of As-S system is observed at deviations of composition from $\mathrm{As}_{40} \mathrm{~S}_{60}$ only on 1 at. \% towards the side of arsenic enrichment [9].

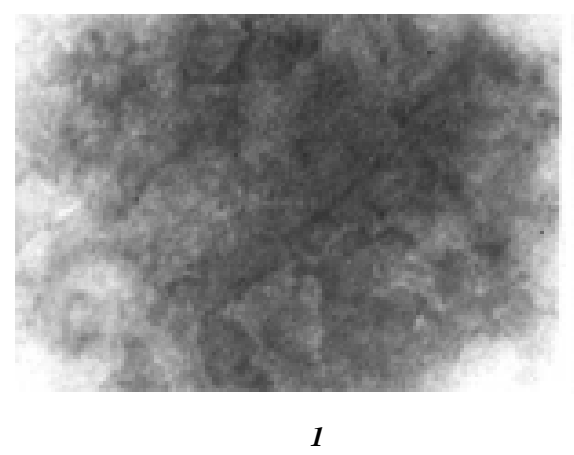

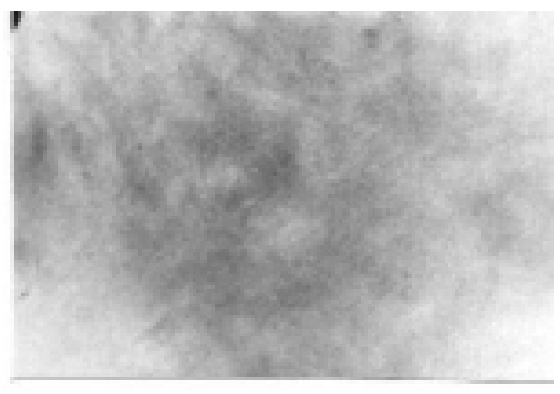

2

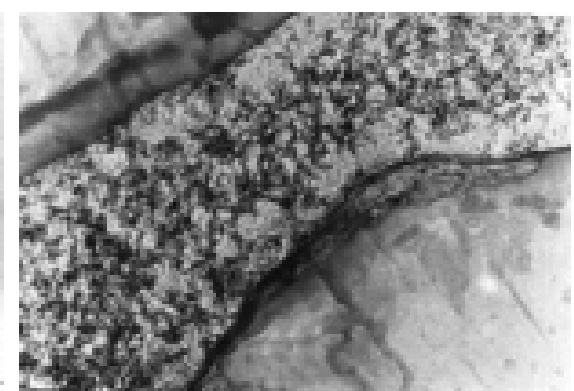

3

Fig. 4. Electron-microscopic images of $g-\mathrm{As}_{2} \mathrm{~S}_{3}$, obtained in different physico-technological conditions [7]: $1-T_{2} V_{1} ; 2-T_{2} V_{2} ; 3-T_{2} V_{3}$. $S Q O, 7(3), 2004$ 


\section{N. Mateleshko et al.: Raman spectra and electron microscopic investigations of ...}

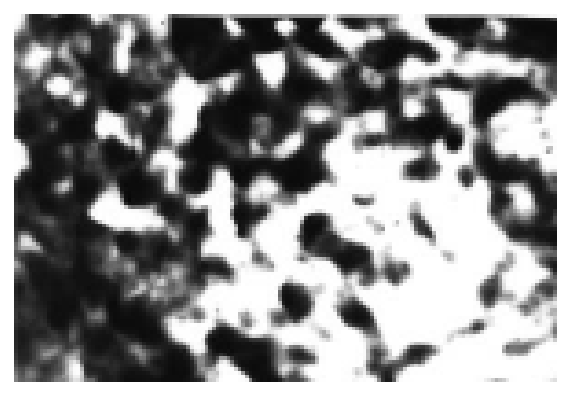

1

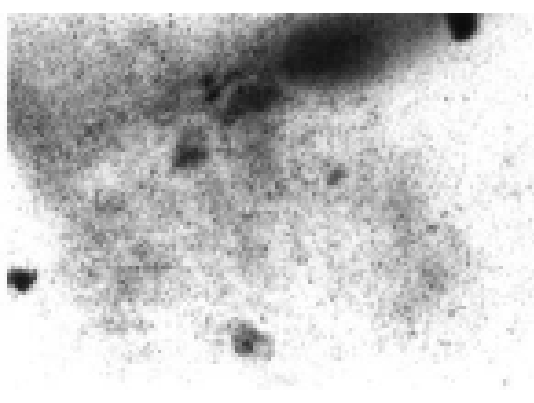

2

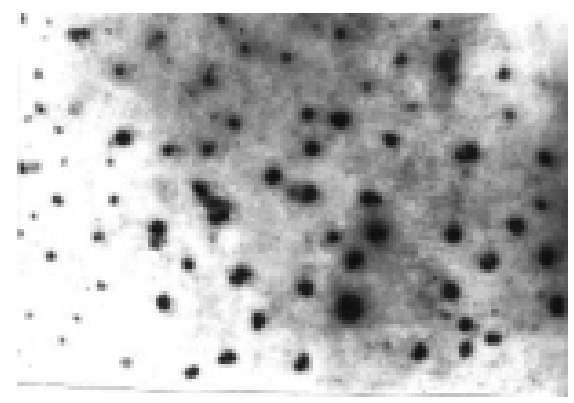

3

Fig. 5. Electron-microscopic images of $g-\mathrm{As}_{2} \mathrm{~S}_{3}$, obtained in different physico-technological conditions [7]: $1-T_{3} V_{1} ; 2-T_{3} V_{2} ; 3-T_{3} V_{3}$.

Thus, it is possible to suppose that non-equilibrium of the glasses fabrication conditions at $T_{1} V_{3}, T_{2} V_{3}$ results in local deviations from $\mathrm{As}_{40} \mathrm{~S}_{60}$ composition, causes appearance of $\mathrm{As}_{4} \mathrm{~S}_{4}$ in micropores, which leads to the infringements of the connectivity of the glass matrix structure. The consequent increase of the temperature up to $T_{3}$ (Fig. 5) increases the melt dissociation degree, and rigid cooling in the non-equilibrium conditions leads to more pronounced local deviations in the composition, which facilitates the microscopic inclusions appearance. The best conditions of $g-\mathrm{As}_{2} \mathrm{~S}_{3}$ fabrication are realized at $T_{1}=$ $=870 \mathrm{~K}$ and $V_{2}=1.5 \mathrm{~K} / \mathrm{s}$.

1. V.S. Minaev, Vitreous semiconductor alloys, Metallurgiya, Moscow, 1991, $407 \mathrm{p}$.

2. S.V. Svechnikov, V.V. Khiminets, N.I. Dovgoshei, Non-crystalline chalcogenides and chalcohalogenides in optoelectronics and microelectronics, Naukova Dumka, Kyiv, 1992, $292 \mathrm{p}$.

3. I.Z. Indutnyi, M.T. Kostishin, O.P. Kasyarum, et al., Photostructural interactions in the metal-semiconductor structures, Naukova Dumka, Kyiv, 1992, 240 p.

4. S. Kokenyesi, V. Mitsa, I. Beszeda, T. Hadhazy, Nemkritalyos szilard anyagok szerkezete es spektroszkoiai vizsgalata, Nyiregyhaza-Ungvar. Patent., Uzhgorod, p. 102 (1994).
5. A.A. Aivazov, B.G. Budagyan, S.P. Vikhrov, A.I. Popov, Noncrystalline semiconductors, M.: High School., p. 356 (1995).

6. A.M. Andriesh Ed., Vitreous semiconductors for optoelectronics, Kishinev, Shtiintsa, P. 198 (1991).

7. O.V. Luksha, E.I. Borkach, V.P. Ivanitsky, Structural-technological modification of $\mathrm{As}_{2} \mathrm{~S}_{3}$ glasses // Journal of Optoelectronics and Advanced Materials, 4(1), p. 45-50 (2002).

8. G. Lucovsky Optic modes in amorphous $\mathrm{As}_{2} \mathrm{~S}_{3}$ and $\mathrm{As}_{2} \mathrm{Se}_{3} / /$ Phys. Rev. B, 6, p. 1480-1489 (1971).

9. V. Mitsa, Vibration spectra and Structure Correlations in OxegenFree Glassy Alloys, UMK VO Publ., Kiev, 1992 (in Russian).

10. T. Mori, K. Matsuishi, K. Arai, Vibrational properties and network topology of amorphous As-S system // J. Non-Cryst. Sol., 65(2), p. 269-283 (1974).

11. W. Bues, M. Somer, W. Brockner, Shwinguns spectren von $\mathrm{As}_{4} \mathrm{~S}_{4}$ and $\mathrm{As}_{4} \mathrm{Se}_{4} / /$ Z. Anorg. Allg. Chem., 499(1), S. 7-14. 80 (1983).

12. S. Mamedov, A. Kisliuk, D. Quitmann, Effect of preparation conditions on the low frequency Raman spectrum of glassy $\mathrm{As}_{2} \mathrm{~S}_{3} / /$ Journal of Materials Science, 33, p. $41-43$ (1998).

13. M.F. Thorpe, B.R. Diordjevich, D.J. Jacobs, The structure and mechanical properties of networks // Amorphous Insulators and Semiconductors. Ed. Kluwer Academic Publisher. p. 289-328 (1997).

14. C.J. Brabec, Structural model of amorphous arsenic sulfide // Phys. Rev. B, 44(24) p. 13332-13342 (1991).

15. T.P. Martin, Arsenic sulfide clusters // Solid State Communication, 44(2) p. 111-114 (1984). 